\title{
A Mutant of Escherichia coli with a Defect in Energy Metabolism
}

\author{
By G. TURNOCK, SANDRA K. ERICKSON, B. A. C. ACKRELL \\ AND BARBARA BIRCH \\ Department of Biochemistry, University of Leicester, Leicester, LEI $7 R H$
}

(Accepted for publication I6 December I97I)

\begin{abstract}
SUMMARY
A mutant of Escherichia coli with a decreased growth efficiency has been investigated. The results of growth studies with different substrates and of measurement of $\mathrm{P} / \mathrm{O}$ ratios in membrane preparations suggest that the strain is defective in the ability to couple synthesis of ATP to electron transport.
\end{abstract}

\section{INTRODUCTION}

Escherichia coli strain I 5-28 is a mutant containing an abnormally high concentration of the immediate precursor to the $50 s$ ribosomal subunit (MacDonald, Turnock \& Forchhammer, 1967). The strain grows much less quickly than the wild-type and a genetic analysis (Turnock, 1969) showed that at least two mutations are responsible for its complex phenotype. One of these mutations ( $b^{-}$; Turnock, I969) confers upon the cell an altered response to the antibiotic streptomycin and a decreased efficiency in the utilization of the growth substrate, compared to the parent strain. The latter property is examined in this paper; the results obtained suggest that the mutation reduces the efficiency of energy metabolism, probably that associated with oxidative phosphorylation. The significance of this finding and ways in which other mutants defective in oxidative phosphorylation might be selected are discussed.

\section{METHODS}

Strains of Escherichia coli. The two strains, $b^{-}$and $b^{+}$, used in this paper were obtained by mating Hfr $15-5$ with strain $15-28 \mathrm{H}$ (Turnock, 1969). They both carry the same str and thy alleles, but do not contain the mutation responsible for the high concentration of ribosome precursor in strain $15-28$.

Media and growth conditions. Unless otherwise stated, liquid cultures were grown with aeration by shaking at $37^{\circ}$. Culture population densities were measured spectrophotometrically at $450 \mathrm{~nm}$ with a Gilford microsample spectrophotometer (light path, I $\mathrm{cm}$ ). The minimal salts medium used was that of Turnock (1969), supplemented with thymine (Io $\mathrm{mg} / \mathrm{l}$ ) and glucose $(2 \mathrm{~g} / 1)$ or carbon source as indicated. For the preparation of cell-free extracts the bacteria were grown in minimal medium with glucose as carbon source supplemented with $\mathrm{I} \%$ vitamin-free Casamino acids.

For growth under anaerobic conditions, inocula were grown in screw-capped bottles filled to the neck with medium and diluted into growth flasks bubbled with $95 \% \mathrm{~N}_{2}, 5 \% \mathrm{CO}_{2}$. When $\mathrm{NO}_{3}{ }^{-}$(as $0.1 \% \mathrm{KNO}_{3}$ ) was used as the terminal electron acceptor, the flasks were bubbled with $\mathrm{N}_{2}$, and $\mathrm{NaHCO}_{3}$ (25 mM) included in the medium (Cox et al. 1970).

Growth yields. The extinction of the culture, measured at $450 \mathrm{~nm}$, is proportional to the cell mass (Schaechter, Maaløe \& Kjeldgaard, 1958) and so this parameter was employed to 
assess growth yields. Cultures were grown with a limiting amount of the carbon source and the extinctions at $450 \mathrm{~nm}$ followed during growth until the stationary phase was reached.

Oxygen consumption by whole cells. The rate of $\mathrm{O}_{2}$ consumption by whole cells was determined polarographically with a Clark oxygen electrode.

Incorporation of $\left[{ }^{14} \mathrm{C}\right]$ acetate. Cultures were grown in glucose minimal medium containing $\left[2-{ }^{14} \mathrm{C}\right]$ acetate $(2 \mathrm{mM}$; specific activity $=2 \mathrm{mCi} / \mathrm{mmol})$. To determine the amount of radioactivity incorporated into cell material, $0.5 \mathrm{ml}$ samples were added to an equal volume of cold $10 \%(\mathrm{w} / \mathrm{v})$ trichloroacetic acid. The precipitates were collected on membrane filters, washed with three $2 \mathrm{ml}$ portions of $5 \%(\mathrm{w} / \mathrm{v})$ trichloroacetic acid, dried and assayed for radioactivity in a liquid scintillation counter.

Incorporation of $\left[{ }^{14} \mathrm{C}\right]$ lactate. Cultures were grown in minimal medium with $\mathrm{DL}-\left[\mathrm{I}-{ }^{14} \mathrm{C}\right] \mathrm{lac}-$ tate $(15 \mathrm{~mm}$; specific activity $=0.8 \mu \mathrm{Ci} / \mathrm{mmol}$ ) as the sole source of carbon. Organisms from $0.5 \mathrm{ml}$ of culture were collected on a membrane filter and washed with three $4 \mathrm{ml}$ portions of minimal salts medium. After drying, radioactivity was assayed in a liquid scintillation counter. Radioactivity remaining in the growth medium was determined on $0.1 \mathrm{ml}$ samples of the initial filtrate.

Mating experiments. These were carried out as described by Turnock (1969).

Preparation of electron transport particles. Harvested cells were washed with $0.0 \mathrm{I}$ M-tris $\mathrm{HCl}$ buffer $\left(\mathrm{pH}_{7} \cdot 4\right)$ and resuspended in the same buffer $(4 \mathrm{ml}$ buffer/g wet wt cells). Extracts were prepared using an MSE ultrasonic disintegrator $\left(2\right.$ min treatment at $0^{\circ}$ ) and unbroken cells removed by centrifuging for $10 \mathrm{~min}$ at $10000 \mathrm{~g}$. The supernatant was removed and centrifuged for $90 \mathrm{~min}$ at $77000 \mathrm{~g}\left(2^{\circ}\right)$ and the pellet resuspended in $0.0 \mathrm{I}$ M-tris $\mathrm{HCl}$ buffer $(\mathrm{pH} 7 \cdot 4)$.

Determination of cytochrome contents. Reflectance spectra of whole cells utilizing endogenous substrate were obtained using the reflectance attachment in a Shimadzu MPS $50 \mathrm{~L}$ spectrophotometer. The concentration of the cytochromes was determined by the difference in reflectance units between 560 to $570 \mathrm{~nm}$ for cytochrome $b_{1}$ and between 625 to $640 \mathrm{~nm}$ for cytochrome $a_{2}$.

Difference spectra of electron transport particles, dithionite reduced minus oxidized and dithionite reduced $+\mathrm{CO}$ minus dithionite reduced, were obtained using a Shimadzu MPS $50 \mathrm{~L}$ spectrophotometer. Concentrations of cytochrome $b_{1}$ were calculated according to Deeb \& Hager (1964), and cytochrome $o$ according to Tabor \& Morrison (I964). Cytochrome $a_{2}$ was in too low a concentration to be determined quantitatively.

Determination of quinone contents. The quinones from frozen whole cells were extracted, chromatographed and determined according to Bishop, Pandya \& King (I962).

Oxidative phosphorylation in phosphorylating particles. The procedure used for preparation of the particles and measurement of oxidative phosphorylation was that developed for the analysis of oxidative phosphorylation of Azotobacter vinelandii by Ackrell \& Jones (I97I).

Assay of adenosine triphosphatase activity. Phosphorylating particles were prepared as above. ATP (I $\mu \mathrm{mol}$ ) was added to $2.0 \mathrm{ml}$ of the membrane preparation in $42 \mathrm{~mm}$ piperazine- $N, N^{\prime}$-bis-[2-ethane sulphonic acid]-acetate buffer, $\mathrm{pH} 6.8$, containing $8 \mathrm{mM} \mathrm{Mg}$ acetate, and the reaction mixture incubated at $30^{\circ}$. At intervals, $20 \mu \mathrm{l}$ samples were transferred to Io $\mathrm{ml}$ water in a boiling water bath to stop enzyme action, the tubes chilled in ice and $0.2 \mathrm{ml}$ samples used to assay ATP using the firefly luciferase method (Welsch \& Smith, 1969). 


\section{Table I. Growth of $b^{+}$and $b^{-}$strains of Escherichia coli ${ }_{15}$ on different carbon sources under aerobic conditions}

$\begin{array}{lccc}\text { Carbon source } & \text { Mean generation time (min) } & \begin{array}{c}\text { Relative } \\ \text { growth yield }\end{array} \\ \text { Glucose, } 3.5 \mathrm{mM} & b^{+} & b^{-} & b^{-} / b^{+} \\ \text {Fructose, } 3.5 \mathrm{mM} & 47 & 55 & 0.57 \\ \text { Lactose, } 3.5 \mathrm{~mm} & - & - & 0.57 \\ \text { Succinate, } 20 \mathrm{mM} & - & - & 0.58 \\ \text { Malate, } 20 \mathrm{mM} & 63 & 210 & 0.33 \\ \text { Lactate, } 20 \mathrm{mM} & 62 & 170 & 0.30 \\ & 6 \mathrm{r} & 122 & 0.36\end{array}$

RESULTS

Efficiency of aerobic growth

Table I compares the mean generation times and relative growth yields of the $b^{-}$and $b^{+}$ strain grown on different carbon sources under aerobic conditions. The mutant grew more slowly in all the media tested, the difference between the two strains being most marked for those substrates (succinate, lactate, malate) that can only be metabolized aerobically. There was also a significant reduction in relative growth yields with these substrates compared to those obtained with glucose, fructose and lactose. However, the growth yield of the mutant with glucose itself was only $57 \%$ of that of the $b^{+}$strain. This increase in consumption of glucose was accompanied by a corresponding increase in the utilization of $\mathrm{O}_{2}$ during growth on glucose, a result that suggests that the oxidation of glucose is unimpaired in the mutant.

The data on growth yields in Table I were obtained by measuring the extinctions of cultures as they entered stationary phase. For glucose the utilization of the carbon source during exponential growth was also determined and corresponded closely to the relative final yields. Thus strains $b^{-}$and $b^{+}$used, respectively, 702 and $431 \mu \mathrm{g}$ glucose $/ \mathrm{ml}$ for synthesis of an amount of cell material corresponding to an $E_{450}$ of I $\cdot 0$.

In the experiment just described it could be argued that the decreased growth yield of the mutant might be due to an impaired ability to use metabolites derived from glucose. This possibility was investigated using one of the substrates (lactate) that can only be metabolized aerobically. In one experiment (Fig. I) the utilization of $\left[\mathrm{I}-{ }^{14} \mathrm{C}\right]$ lactate was monitored. Clearly (Fig. I $a$ ) the two strains synthesized cell material of the same specific activity from the specifically labelled substrate, although (Fig. I $b$ ) the mutant used approximately three times as much lactate as the $b^{+}$strain for the synthesis of unit cell mass. The second part of the experiment also demonstrates that growth of the mutant on lactate is not accompanied by the accumulation of (radioactive) products of partial metabolism in the medium.

The uptake of $\mathrm{O}_{2}$ by the two strains grown on lactate was also determined. Cells harvested during exponential growth on lactate were washed and mixed with a limiting amount of lactate in a reaction vessel containing an oxygen electrode. The mutant and wild-type strains used, respectively, $2 \cdot 2$ and $\mathrm{I} \cdot 7 \mu \mathrm{g}$ atoms $\mathrm{O} / \mu \mathrm{mol}$ ctate. The mutant oxidized the substrate nearly $50 \%$ more rapidly than did the normal strain.

\section{Growth on glucose under different conditions}

Table 2 compares the growth rates and growth yields of the $b^{-}$and $b^{+}$strains with glucose as carbon source under anaerobic conditions or with $\mathrm{O}_{2}$ or $\mathrm{NO}_{3}{ }^{-}$as terminal electron acceptor. Although the $b^{-}$strain could be grown in screw-capped bottles filled to the neck with medium (Turnock, 1969), subsequent dilution of such cultures into flasks bubbled with 


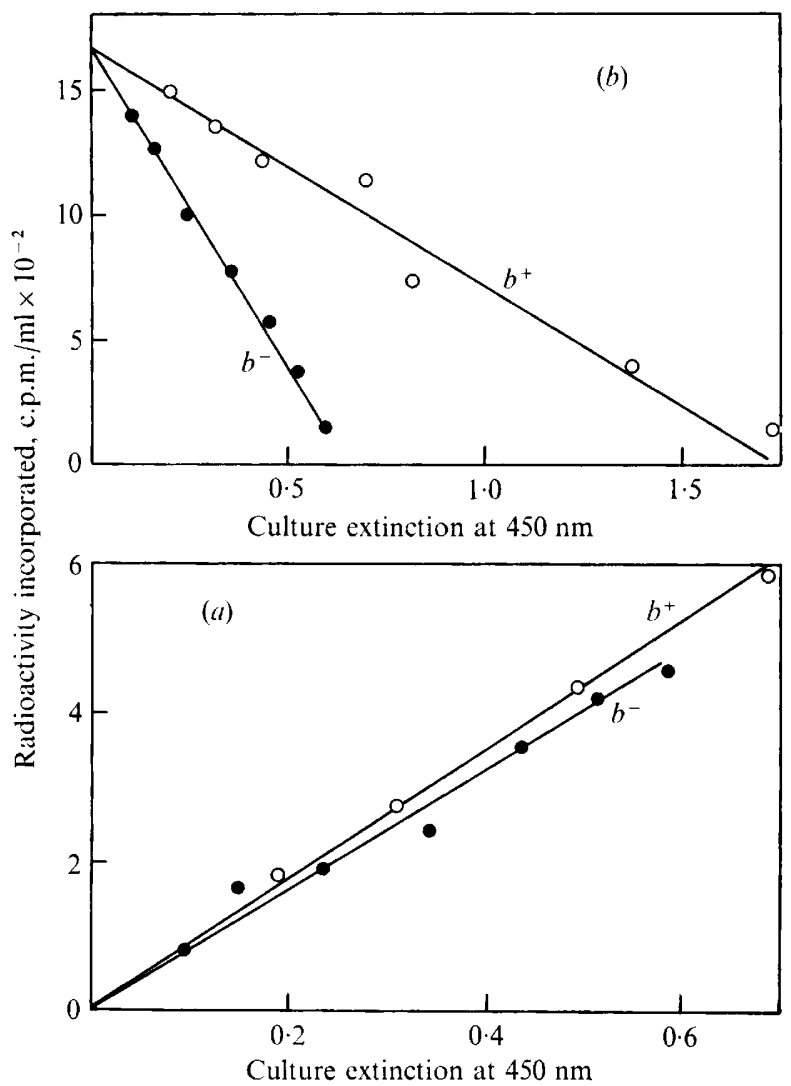

Fig. I. Utilization of $\left[\mathrm{I}^{14} \mathrm{C}\right]$ lactate during growth in lactate minimal medium. (a) Incorporation into cell material. $(b)$ Loss of radioactivity from the growth medium. In $(a)$ the scale for the culture extinction is expanded to enable the results for the two strains to be compared in detail up to the point at which the mutant ceased to grow.

Table 2. Growth of $b^{-}$and $b^{+}$strains of Escherichia coli $\mathrm{I} 5$ on glucose under different conditions

\begin{tabular}{lcc}
\multicolumn{1}{c}{ Condition } & $\begin{array}{c}\text { Mean } \\
\text { generation } \\
\text { time (min) }\end{array}$ & $\begin{array}{c}\text { Growth } \\
\text { yield, } E_{\mathbf{4 5 0} \mathrm{nm}}\end{array}$ \\
$b^{+}$, aerobic & 47 & $\mathrm{I} \cdot 76$ \\
$b^{+}$, anaerobic & 60 & 0.68 \\
$b^{+}$, anaerobic/nitrate & 52 & $\mathrm{I} \cdot \mathrm{I} 7$ \\
$b^{-}$, aerobic & 55 & 0.99 \\
$b^{-}$, anaerobic & - & - \\
$b^{-}$, anaerobic/nitrate & 54 & 0.98
\end{tabular}

$\mathrm{N}_{2} / \mathrm{CO}_{2}$ resulted in rather erratic growth, and it was not possible to obtain reliable growth rates or yields in this way. The reason for this is not understood.

The use of nitrate as terminal electron acceptor yielded very similar results with both strains.

\section{Growth on acetate}

In contrast to the $b^{+}$strain, the mutant did not grow on acetate as the sole source of carbon. However, the mutant was able to incorporate acetate into cell material during growth on glucose (Fig. 2). 


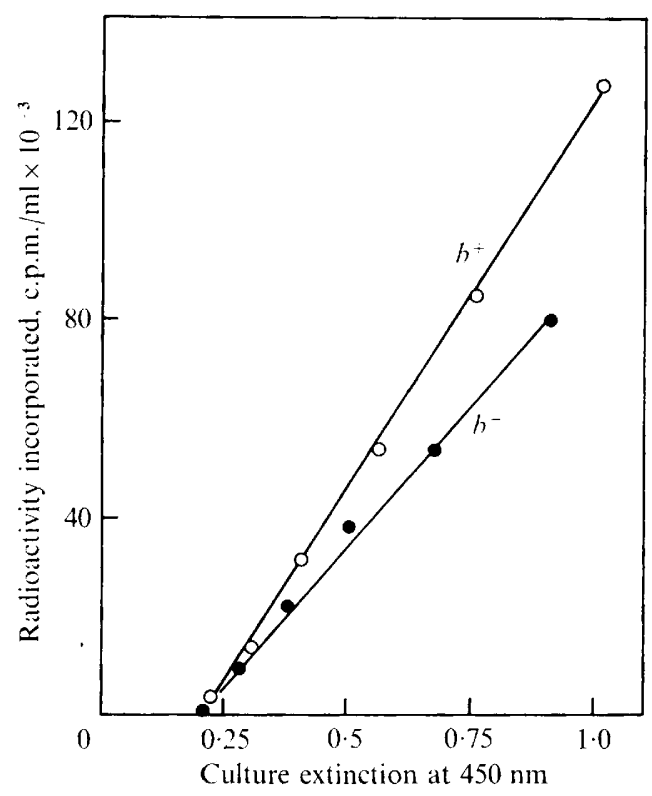

Fig. 2. Incorporation of $\left[2{ }^{14} \mathrm{C}\right]$ acetate into acid-insoluble material during growth in glucose minimal medium supplemented with $\mathrm{Na}$ acetate $(2 \mathrm{mM})$. Labelled acetate was added to the cultures after exponential growth had been established.

Table 3. Components of the electron transport chain in strains $b^{-}$and $b^{+}$of Escherichia coli $\mathrm{I} 5$

(a) Whole cells

\begin{tabular}{|c|c|c|c|c|}
\hline & \multicolumn{2}{|c|}{$\begin{array}{c}\text { Cytochromes } \\
\text { (reflectance units/g dry wt) }\end{array}$} & \multicolumn{2}{|c|}{$\begin{array}{c}\text { Quinone } \\
(\mu \mathrm{mol} / \mathrm{g} \text { dry } \mathrm{wt})\end{array}$} \\
\hline & $b_{1}$ & $a_{2}$ & Ubiquinone & Menaquinone \\
\hline$b^{+}$ & 0.045 & 0.007 & 0.60 & 0.04 \\
\hline$b^{-}$ & $0.06 \mathrm{I}$ & 0.027 & 0.75 & 0.04 \\
\hline
\end{tabular}

(b) Electron transport particles

Cytochromes $(\mu \mathrm{mol} / \mathrm{g}$ protein)

$\begin{array}{cccc} & b_{1} & a_{2} & o \\ b^{+} & 0.95 & + & 0.65 \\ b^{-} & 0.87 & + & 0.52\end{array}$

To determine whether the inability of the $b^{-}$strain to grow on acetate could also be due to the mutation responsible for the reduced efficiency of growth on other carbon sources a mating experiment with an $\mathrm{Ace}^{+} \mathrm{Hfr}$ was carried out, and $\mathrm{Ace}^{+}$recombinants examined for the frequency of unselected donor markers $\left(b^{+}, x y l^{+}, \operatorname{str} A^{\mathrm{s}}\right)$. Nutritional counter selection was used to prevent growth of the pyrA male strain (Turnock, 1969). All of the $154 \mathrm{Ace}^{+}$ recombinants tested had the growth characteristic, as shown by colony size (Turnock, 1969), of the $b^{+}$genotype. The frequency of $x y l^{+}$and $s t r A^{\mathrm{s}}$ among the recombinants was similar to that obtained in mating experiments designed to locate the position of the $b^{-}$gene (Turnock, 1969). These results suggest that the decreased efficiency of growth and the inability to grow on acetate of the $b^{-}$strain are due to the same, or to very closely linked, mutations. 


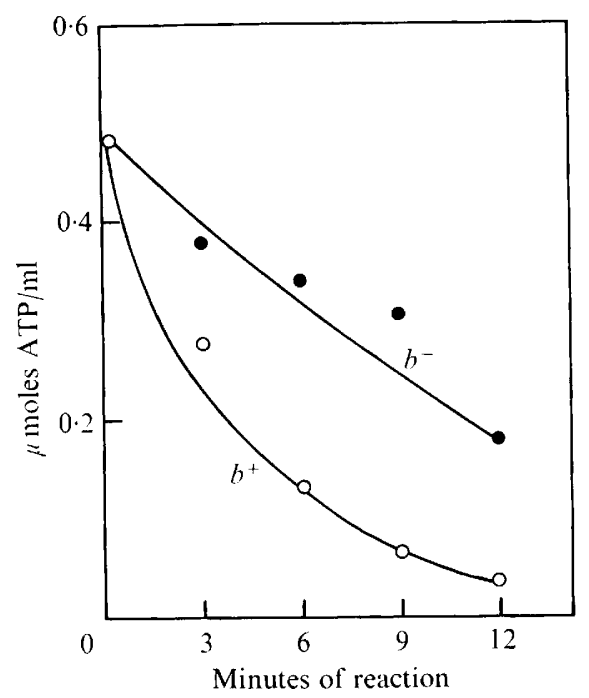

Fig. 3. Assay of adenosine triphosphatase activity in preparations of phosphorylating particles. Each reaction mixture contained $4 \cdot 2 \mathrm{mg}$ protein $/ \mathrm{ml}$.

Table 4. Oxidative phosphorylation in particle preparations from strains $b^{-}$and $b^{+}$of Escherichia coli 15

\begin{tabular}{|c|c|c|c|c|}
\hline Strain & $\begin{array}{l}\text { ATP produced } \\
(\mu \mathrm{mol})\end{array}$ & $\begin{array}{l}\text { Atoms } \mathrm{O} \text { taken up } \\
(\mu \mathrm{g} \text { atoms })\end{array}$ & $\mathrm{P} / \mathrm{O}$ ratio & $\begin{array}{c}\text { activity } \\
\left(\mu \mathrm{g} \text { atoms } \mathrm{O}_{2} /\right. \\
\mathrm{min} / \mathrm{mg} / \text { protein })\end{array}$ \\
\hline$b^{+}$ & $\begin{array}{l}0.795 \\
0.5 \mathrm{I}\end{array}$ & $\begin{array}{l}I \cdot 24 \\
I \cdot 0\end{array}$ & $\begin{array}{l}0.64 \\
0.51\end{array}$ & $\begin{array}{l}0.59 \\
0.34\end{array}$ \\
\hline$b^{-}$ & 0 & $I \cdot 36$ & 0 & 0.52 \\
\hline & 0 & 0.87 & 0 & 0.34 \\
\hline
\end{tabular}

\section{Components of the electron transport chain}

The increased consumption of glucose by the mutant during aerobic growth is accompanied by a corresponding increase in the uptake of oxygen, suggesting that the decreased growth yield cannot be due to the absence of one of the components of the electron transport chain. This was checked by spectral analysis of cell suspensions and of membrane preparations for the presence of cytochromes $b_{1}, a_{2}$ and $o$, and by extraction for quinones. The results are shown in Table 3. The only major difference between the two strains was the greater cytochrome $a_{2}$ content of the mutant. It is unlikely that this is directly associated with the inability of the mutant to obtain energy from electron transport. One possible explanation is that, although cultures of the two strains were harvested during exponential growth and at the same cell density, their physiological state would not be identical since the mutant culture grew less rapidly and less efficiently.

\section{Oxidative phosphorylation in respiratory particles}

The results presented so far are compatible with the idea that the $b^{-}$strain is defective in its ability to couple the synthesis of ATP with electron transfer from substrate to $\mathrm{O}_{2}$. Thus, for example, substrates such as succinate which can only be metabolized aerobically via the 
tricarboxylic acid cycle give relatively lower growth yields than glucose (Table I). To examine this hypothesis directly membrane preparations were tested for the ability to synthesize ATP during electron transfer from $\mathrm{NADH}$ to $\mathrm{O}_{2}$. The data obtained (Table 4) demonstrate clearly that, although both strains had similar NADH-oxidase activities, no ATP synthesis occurred with the mutant preparation in contrast to a measurable $\mathrm{P} / \mathrm{O}$ ratio (compare Kashket \& Brodie, I963) obtained with the $b^{+}$strain. No net synthesis of ATP would occur with membrane preparations from the mutant if they contained a more active adenosine triphosphatase (i.e. able to fully compete for ATP with the hexokinase trapping system) than the $b^{+}$strain. However, comparison of preparations of the $b^{+}$and $b^{-}$strains for ATPase activity under the conditions used for the determination of $\mathrm{P} / \mathrm{O}$ ratios (minus an ATP trapping system) indicated that the mutant had slightly less ATPase activity than the wild-type (Fig. 3).

\section{DISCUSSION}

Two lines of evidence suggest that the $b^{-}$mutation is associated with a defect in energy metabolism: (i) the decreased growth yield with substrates such as succinate that can only be oxidized aerobically, compared to glucose (Table I); (ii) the inability of membrane preparations from the $b^{-}$strain to couple ATP synthesis to the oxidation of NADH (Table 4). However, there must be some synthesis of ATP coupled to electron transport in the intact $b^{-}$cell under aerobic conditions. This is shown by the fact that growth does occur with substrates that can only be metabolized aerobically, and is also demonstrated by the growth yield of the mutant metabolizing glucose under aerobic conditions, being higher than is possible by substrate-level phosphorylation alone.

The defect in energy metabolism in the mutant does not seem to be due to the absence of a component of the electron transport chain. Thus, the higher glucose consumption of the mutant was accompanied by increased uptake of $\mathrm{O}_{2}$ and the quinone and cytochrome contents of both strains were similar, as were the NADH-oxidase activities of membrane preparations (Table 4). A mutant of Escherichia coli lacking a component of the electron transport chain (i.e. ubiquinone) has been described by Cox et al. (I970). This strain, in contrast to the $b^{-}$mutant, had a greatly impaired ability to oxidize NADH in cell-free preparations and had an aerobic growth yield with glucose characteristic of anaerobic growth.

The nature of the biochemical lesion in the mutant which we have studied is not known. Although understanding of the mechanism of oxidative phosphorylation in bacteria is still rudimentary, one possibility, apart from those concerning a lesion in one of the coupling factors, is a structural defect in the organization of the membrane in which the electron transport chain is located, so decreasing the efficiency of coupling of ATP synthesis to electron transport. An alteration of the membrane could also explain the poor growth of the mutant under anaerobic conditions. In previous work (Turnock, 1970) cultures of a $b^{-}$ strain were grown satisfactorily in glucose minimal medium, gassed with $\mathrm{N}_{2}$, in the presence of glutamate $(350 \mu \mathrm{g} / \mathrm{ml})$ to compensate for loss of $\mathrm{CO}_{2}$. This, in contrast to the erratic growth in cultures gassed with $\mathrm{N}_{2} / \mathrm{CO}_{2}$, suggests that the cell membrane is in some circumstances abnormally leaky to metabolic intermediates. The greater sensitivity of $b^{-}$strains to streptomycin has also been ascribed to an alteration in the membrane (Turnock, 1970), although genetic evidence that the two phenomena are due to the same mutation is lacking.

In the absence of $\mathrm{O}_{2}$, both $b^{-}$and $b^{+}$strains had very similar growth rates and growth yields with $\mathrm{NO}_{3}{ }^{-}$as terminal electron acceptor. Again, if the basic lesion involved a membrane component, this could have a minimal effect on the organization and efficiency of the 
electron transport chain in nitrate grown $b^{-}$organisms compared to that in aerobically grown bacteria.

The genetic analysis suggests that the inability of the $b^{-}$strain to grow on acetate, and its decreased growth efficiency with other carbon sources, are due to the same, or to very closely linked, mutations. The growth yield with acetate in Escherichia coli is not very high and ATP is required for the first reaction in the pathway of utilization. An organism with a defect in energy metabolism may therefore not be able to obtain sufficient energy to permit net growth.

The $b^{-}$mutation is situated at about 72 to $73 \mathrm{~min}$ on the chromosome map of Escherichia coli (Turnock, I969). As stated earlier, rigorous genetic evidence that only one mutation is responsible for the $b^{-}$phenotype is not available; 15 thy strains of $E$. coli are not amenable to transduction by the bacteriophages normally used for this purpose (G. Turnock, S. K. Erickson, B. A. C. Ackrell \& B. Birch, unpublished experiments). An attempt to isolate spontaneous Ace ${ }^{+}$revertants of $b^{-}$strain has not so far been successful, suggesting that the strain may still be genetically complex.

Despite its possibly complex nature the properties of the $b^{-}$mutant do indicate ways in which other strains defective in energy metabolism might be isolated. One such method would be to screen Ace $^{-}$strains for a decreased efficiency of growth on glucose. If such mutants can be isolated from Escherichia coli KI 2 they could be of considerable value in elucidating both the genetic organization of the electron transport system and further details of the coupling of ATP to electron transport. The work of Gibson and his colleagues on Ubi mutants (Cox et al. 1970) has already demonstrated the value of this approach.

Whilst this paper was in preparation Butlin, Cox \& Gibson (1971) published a description of two mutants of Escherichia coli with some properties similar to those of the $b^{-}$strain. The strains, designated unc $A$ were selected on the basis of their inability to use succinate or lactate as a source of carbon, and they also have a low aerobic growth yield with glucose. Evidence is presented that the mutants have lost $\mathrm{Mg}^{2+}, \mathrm{Ca}^{2+}$-stimulated adenosine triphosphatase and that this enzyme is essential for oxidative phosphorylation in Escherichia coli. The unc $A$ gene is located at $73.5 \mathrm{~min}$ on the genetic map - that is to say, in the same region of the chromosome as the $b^{-}$gene (Turnock, 1969). Although Butlin et al. (I97I) assayed adenosine triphosphatase under different conditions to those employed in this paper, making precise comparison difficult, membrane preparations from the $b^{-}$strain did possess ATPase activity albeit less than the normal strain (Fig. 3). The ability of the $b^{-}$strain to grow on succinate and lactate is a further point of difference between it and the unc $A$ mutants.

We wish to thank Professor H. L. Kornberg and Dr C. W. Jones for advice and encouragement.

\section{REFERENCES}

ACKRell, B. A. C. \& Jones, C. W. (197I). The respiratory system of Azotobacter vinelandii. I. Properties of phosphorylating respiratory membranes. European Journal of Biochemistry 20, 22-28.

Bishop, D. H. L., Pandya, K. P. \& KING, H. K. (1962). Ubiquinone and vitamin K in bacteria. Biochemical Journal 83, 606-6i 4 .

Butlin, J. D., Cox, G. B. \& Gibson, F. (1971). Oxidative phosphorylation in Escherichia coli K12. Biochemical Journal 124, 75-8I.

Cox, G. B., Newton, N. A., Gibson, F., Snowswell, A. M., \& Hamilton, J. A. (I970). The function of ubiquinone in Escherichia coli. Biochemical Journal $117,55 \mathrm{I}-562$.

DeEb, S. S. \& HAGER, L. P. (1964). Crystalline cytochrome $b_{1}$ from Echerichia coli. Journal of Biological Chemistry 239, 1024-103I. 
KASHKET, E. R. \& BRODIE, A. F. (I963). Oxidative phosphorylation in fractionated bacterial systems. VIII. Role of particulate and soluble fractions from Escherichia coli. Biochimica et biophysica acta 78, 52-65.

MacDonald, R. E., Turnock, G. \& ForchHammer, J. (1967). The synthesis and function of ribosomes in a new mutant of Escherichia coli. Proceedings of the National Academy of Sciences of the United States of America 57, I4I-I47.

Schaechter, M., MaAløe, O. \& KJeldgaAdd, N. O. (1958). Dependency on medium and temperature of cell size and chemical composition during balanced growth of Salmonella typhimurium. Journal of General Microbiology 19, 607-616.

TABOR, H. W. \& Morrison, M. (1964). Electron transport in Staphylococci. Properties of a particle preparation from exponential phase Staphylococcus aureus. Archives of Biochemistry and Biophysics 105, 367-379.

TURNocK, G. (1969). A genetic analysis of a mutant of Escherichia coli with a defect in the assembly of ribosomes. Molecular and General Genetics 104, 295-312.

TURNock, G. (1971). The action of streptomycin in a mutant of Escherichia coli with increased sensitivity to the antibiotic. Biochemical Journal I18, 659-666.

WeLSCH, F. \& SMITH,L. (1969). Kinetics of synthesis and utilisation of adenosine triophosphate by intact cells of Rhodospirillum rubrum. Biochemistry 8, 3403-3408. 